\title{
Erratum to: Synthesis, Thermoresponsive Behavior, and Catalytic Properties of Amphiphilic Diblock Copolymers of $N$-Vinylcaprolactam and $N$-Vinylimidazole
}

\author{
A. I. Barabanova ${ }^{a}$, I. V. Blagodatskikh ${ }^{a, *}$, O. V. Vyshivannaya ${ }^{a}$, A. V. Muranov ${ }^{a}$, \\ A. S. Peregudov ${ }^{a}$, and A. R. Khokhlov ${ }^{a, b}$ \\ ${ }^{a}$ A.N. Nesmeyanov Institute of Organoelement Compounds, Russian Academy of Sciences, Moscow, 119991 Russia \\ ${ }^{b}$ Faculty of Physics, Moscow State University, Moscow, 119991 Russia \\ *e-mail: blago@ineos.ac.ru \\ Received August 30, 2021; revised August 30, 2021; accepted August 30, 2021
}

DOI: $10.1134 / \mathrm{S} 0965545 \mathrm{X} 21340010$

The article "Synthesis, Thermoresponsive Behavior, and Catalytic Properties of Amphiphilic Diblock Copolymers of $N$-Vinylcaprolactam and $N$-Vinylimidazole," written by A. I. Barabanova, I. V. Blagodatskikh, O. V. Vyshivannaya, A. V. Muranov, A. S. Peregudov, and A. R. Khokhlov, was originally published electronically in Springer-Link on 12 July 2021 without Open Access. After publication in volume 63, issue 4, pages 382-399 the authors decided to make the article an Open Access publication. Therefore, the copyright of the article has been changed to (C) The Author(s), 2021 and the article is forthwith distributed under the terms of a Creative Commons Attribution 4.0 International License (http://creativecommons.org/licenses/by/4.0/, CC BY), which permits use, duplication, adaptation, distribution and reproduction of a work in any medium or format, as long as you cite the original author(s) and publication source, provide a link to the Creative Commons license, and indicate if changes were made.

The original article can be found online at https://doi.org/10.1134/S0965545X21040027 